\title{
Measuring and monitoring forest degradation for REDD Implications of country circumstances
}

Daniel Murdiyarso, Margaret Skutsch, Manuel Guariguata, Markku Kanninen Cecilia Luttrell, Pita Verweij and Osvaldo Stella

\section{Key points}

- Including forest degradation (along with deforestation) in a REDD agreement will make it more effective in accounting for carbon emissions and more equitable by encouraging additional countries to participate.

- Degradation should be viewed as a different process from deforestation with different actors and drivers.

- Changes in carbon stocks from forest degradation can be monitored using the 'stockdifference' and 'gain-loss' methods. The choice of method will depend largely on countries' data availability and capacity.

- The stock-difference method allows local communities and forest users to monitor the carbon stock changes of their own forest activities; the gain-loss method is primarily intended to use secondary data already available at national level.

- The inclusion of degradation in a REDD agreement should permit flexibility in the development and application of methodologies, allowing countries to build on their existing capacities and circumstances.

\section{Why include degradation in}

\section{a REDD agreement?}

Forest degradation is a major source of greenhouse gas emissions. In the Brazilian Amazon it is responsible for 20 per cent of total emissions (Asner et al. 2005). In Indonesia, the forest stock is decreasing by a rate of six per cent a year, only one-third of which is due to deforestation (Marklund and Schoene 2006). In Africa, the annual rate of degradation is almost 50 per cent of the deforestation rate (Lambin et al. 2003).

In 2007, the Conference of the Parties (COP 13) to the United Nations Framework Convention on Climate Change (UNFCCC) acknowledged the importance of degradation and included it in the proposed mechanism for reducing emissions from deforestation and forest degradation (REDD). Addressing degradation has other important benefits, since it reduces the forest's capacity to adapt to climate change and their ability to provide ecosystem and livelihood services.

Forest degradation often has different driving forces than deforestation, and degradation is not necessarily a precursor to deforestation. Forests can remain degraded for a long time, never becoming totally deforested. So addressing deforestation does not automatically reduce rates of degradation. Failing to include degradation in a REDD agreement could leave considerable amounts of forest-based emissions unaccounted for. For example, a healthy primary forest (e.g. with a crown cover of 70 per cent) could be degraded to 15 per cent of crown cover and still be classified as 'forest' without any accounting for increased emissions. 
This brief focuses on the implications of the methods used to specifically measure and monitor forest degradation and discusses them in terms of costefficiency, effectiveness in emission accounting, and international equity issues that arise from differing country circumstances.

\section{Definition and causes of forest}

\section{degradation}

As adopted at COP 9 in 2003, forest degradation is defined as 'direct human-induced long-term loss (persisting for $X$ years or more) of at least $Y$ per cent of forest carbon stocks (and forest values) since time $(T)$ and not qualifying as deforestation' (IPCC, 2003a). However, reaching agreement on an operational procedure for the monitoring, reporting and verification (MRV) of degradation has been problematic (Penman 2008), as $\mathrm{X}, \mathrm{Y}$ and minimum area are difficult to specify since the values depend on the different degradation activities and forest composition.

Common degrading activities in the tropics include (GOFC-GOLD, 2008):

- Selective logging.

- Large-scale and open forest fires.

- Collection of fuelwood and non-timber forest products.

- Production of charcoal, grazing, sub-canopy fires, shifting cultivation.

Apart from selective logging, little analysis has been made of the impacts of these processes on the loss of forest biomass and the time needed for regrowth. Further, almost all studies have focused on humid tropical forests. However, degradation of dry forests by extraction of fuelwood is often more pronounced than by commercial timber harvesting (Skutsch and Trines 2008), and this is important since dry forests are generally more heavily populated than rainforest. While the carbon content of

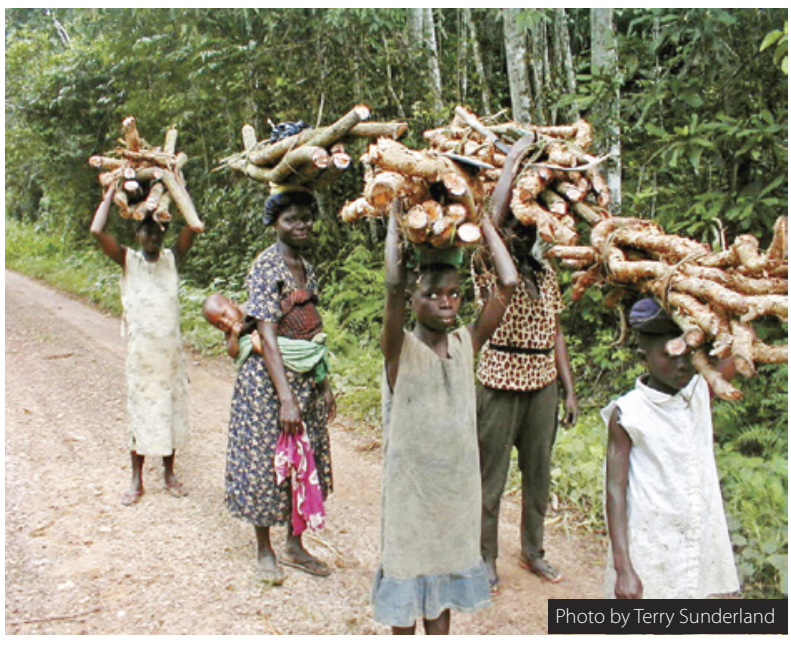

Degradation often has different driving forces to deforestation: collection of Acacia pentagona in Ghana. dry forests is much lower than that of humid forests, dry forests account for 42 per cent of the tropical forest area (Murphy and Lugo 1986).

\section{Methods for estimating emissions from forest degradation}

The IPCC (2003b) defines five carbon pools to be monitored for deforestation and degradation: aboveground biomass, below-ground biomass, litter, dead wood and soil organic carbon. The most practical method is to monitor only above-ground biomass. However, degradation processes such as logging and fires can significantly influence other carbon pools such as dead wood and litter.

The IPCC (2003b) also provides three tiers for estimating emissions, with increasing levels of data requirements and analytical complexity and therefore increasing accuracy:

- Tier 1 uses default emission factors (indirect estimation of the emissions based on canopy cover reduction) for forest activities ('activity data') that are collected nationally or globally.

- Tier 2 applies emission factors and activity data from country-specific data.

- Tier 3 uses methods, models and inventory measurement systems that are repeated over time, driven by high-resolution activity data and disaggregated sub-nationally at a finer scale.

The MRV of deforestation and degradation requires monitoring of two components: (1) changes in forest area by forest type and (2) average carbon stocks per unit area and forest type (IPCC 2003b). Thus, the simplest approach (Tier 1 ) keeps track of area changes within forest categories and uses global default values for carbon densities of those forest categories. At Tier 2, the accuracy is increased by estimating carbon densities using country-specific data instead of global default values. At Tier 3, models and inventory systems are tailored to national circumstances and repeated over time, thus also measuring changes in carbon densities within the accounting period.

Changes in forest area can be monitored by remote sensing, at least in part, or by systematic forest inventories with a sample size large enough to detect significant changes in forest area by forest type. Monitoring changes in areas subject to forest degradation (i.e. the change from intact forest to disturbed forest) is much more challenging for remote sensing than monitoring deforestation. Deforestation is easily detected from space, particularly when it occurs on a large scale. However, forest degradation, such as the removal of a few trees per hectare (selective logging) or undergrowth (by fire) or branches and small trees (for fuelwood) is much more difficult to observe remotely. These activities affect the canopy cover only minimally but can affect the forest stock significantly (DeFries et al. 2007). Even 
with high-resolution optical imagery, it is hard to detect under-canopy changes: advanced methods such as radar, which do have this potential, are only applicable in small areas.

One possible way of dealing with this problem is to use a probabilistic approach. This involves stratifying forest by risk of degradation, based on observation of past trends and related to proxy variables such as accessibility (e.g., density of road networks, distance from settlements) (Schelhas and Sanchez-Azofeifa 2006). The parameters in this kind of modelling would be different for different types of degradation processes (e.g., selective logging, fuelwood collection) (Iskandar et al. 2006).

Changes in average carbon stocks per unit area per forest type can be monitored using various methods, including secondary datasets and estimations from IPCC (2003b), as well as in situ forest inventories and sampling using permanent plots. To measure changes in carbon stocks for degradation, IPCC (2006) recommends two options: the stock-difference method and the gain-loss method (see Figure 1).

The stock-difference method builds on traditional forest inventories to estimate sequestration or emissions. The gain-loss method is built upon an ecological understanding of how forests grow and upon information on natural or anthropogenic processes producing carbon losses. With the stock-difference method, carbon stocks in each carbon pool are estimated by measuring the actual stock of biomass at the beginning and end of the accounting period. With the gain-loss method, biomass gains are estimated on the basis of typical growth rates in terms of mean annual increment (MAI) minus biomass losses estimated from activities such as timber harvesting, logging damage, fuelwood collection and overgrazing as well as from fire. If the forest is stratified into areas subject to different degradation processes, and these are well understood, it may be possible to estimate with some accuracy the quantity of wood products extracted in a given period.

Table 1 compares the stock-difference method with the gain-loss method, both of which could be used for degradation assessment using IPCC Tiers 2 and 3. The choice of method will depend largely on the availability of data and resources to collect additional data (GOFCGOLD 2008). Countries experiencing significant forest degradation may want to develop national and local databases and models to estimate the impact of these changes on different carbon pools in order to use the gain-loss method. Estimates by Hardcastle and Baird (2008) suggest that adding degradation to the cost of Tier 3 reporting only increases the set-up costs by 10 per cent for Democratic Republic of Congo, 11 per cent for Indonesia and 13 per cent for Brazil, with similar percentage increases in recurrent costs. However, these calculations assume that the country is already reporting at Tier 3 and will therefore have a robust sample system (covering a minimum of three per cent of land surface and six strata) in place.

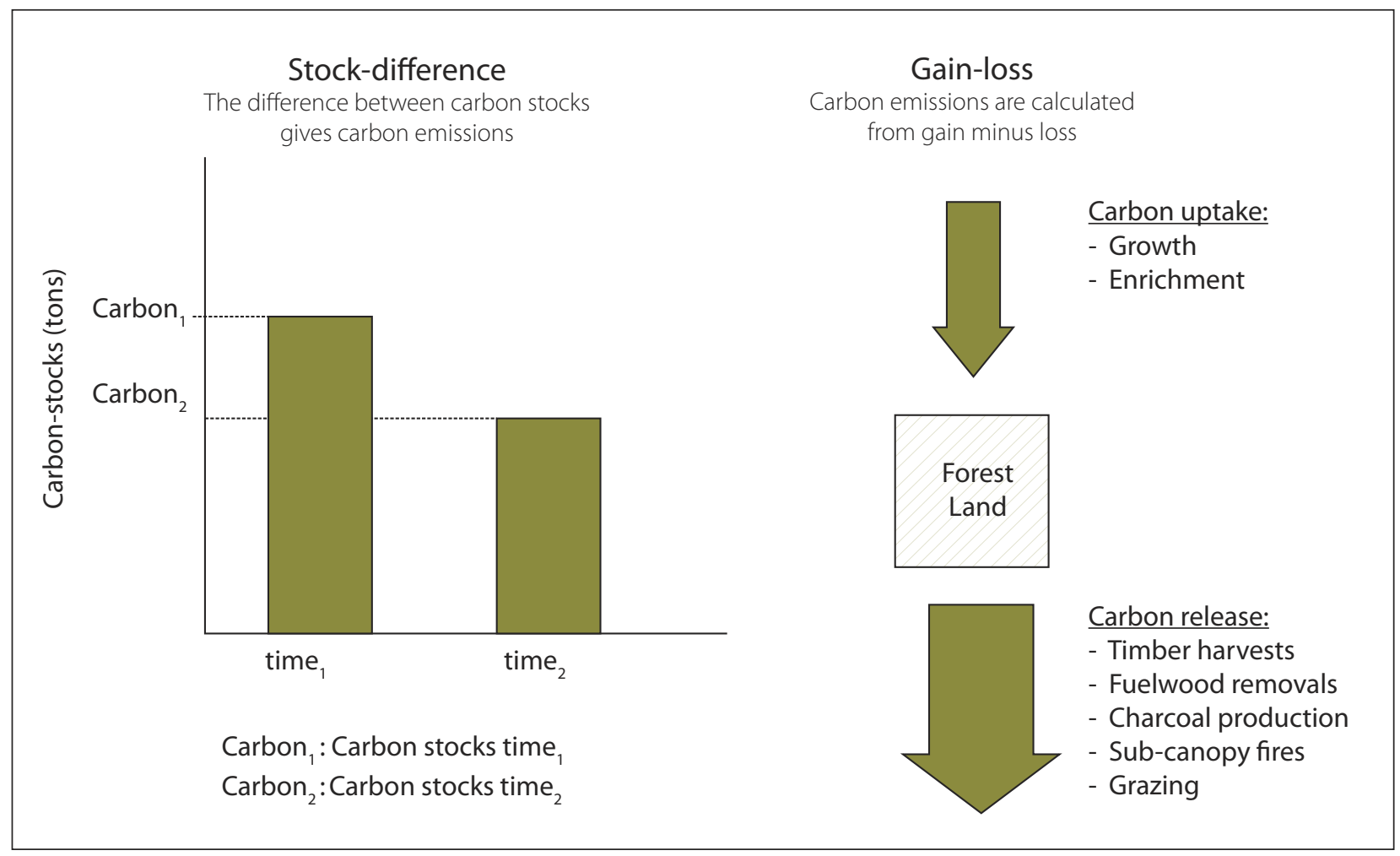

Figure 1. Estimating emissions from forest degradation: comparing the stock-difference and gain-loss methods 
Table 1. Comparison of stock-difference and gain-loss methods for estimating emissions from different types of degradation

\begin{tabular}{|c|c|c|}
\hline Activity & Stock-difference method & Gain-loss method \\
\hline Selective logging & $\begin{array}{l}\text { - Legal harvesting usually requires measurement of biomass after } \\
\text { harvesting, thus necessary data should be available. } \\
\text { - Illegal harvesting would require additional data collection. } \\
\text { - Data on undisturbed forest can be used as a proxy if pre- } \\
\text { harvesting data for particular sites is not available. }\end{array}$ & $\begin{array}{l}\text { - Uses estimates of MAI and centralised } \\
\text { records on timber extraction activities. } \\
\text { - Reliability depends on honesty of timber } \\
\text { companies in reporting rates of extraction. }\end{array}$ \\
\hline Large-scale forest fires & $\begin{array}{l}\text { - Reference data from undisturbed forest can be used for the pre- } \\
\text { fire situation, but forest inventory would be needed to measure } \\
\text { post-fire biomass. }\end{array}$ & $\begin{array}{l}\text { - Losses due to fire can be estimated from } \\
\text { the area burned and emission factors used } \\
\text { to estimate the emissions based on the } \\
\text { biomass lost. }\end{array}$ \\
\hline $\begin{array}{l}\text { Harvesting of } \\
\text { fuelwood and non- } \\
\text { timber forest products }\end{array}$ & $\begin{array}{l}\text { - Pre-harvesting biomass levels could be estimated from typical } \\
\text { levels in undisturbed forest, but in practice much of the forest } \\
\text { subject to these uses will already be partially degraded at the start } \\
\text { of the accounting period. } \\
\text { - In areas already under individual or community management, } \\
\text { pre- and post period forest inventories can be carried out by forest } \\
\text { users. }\end{array}$ & $\begin{array}{l}\text { - Data on losses e.g., registers of commercial } \\
\text { wood-based products, estimates of fuel } \\
\text { wood use) may be available. } \\
\text { - Fuel wood off-take could also be calculated } \\
\text { using population and data on average } \\
\text { household fuel wood consumption. } \\
\text { - Data on gain available from standard MAl } \\
\text { statistics. }\end{array}$ \\
\hline $\begin{array}{l}\text { Sub-canopy fire, } \\
\text { grazing and shifting } \\
\text { cultivation (using } \\
\text { forest for agricultural } \\
\text { production) }\end{array}$ & $\begin{array}{l}\text { - Pre-harvesting biomass levels could be estimated from typical } \\
\text { levels in undisturbed forest, but most forests subject to these } \\
\text { changes will already be partially degraded at the start of the } \\
\text { accounting period. } \\
\text { - Community measurements can be made and can help establish } \\
\text { local 'ownership' of the process. }\end{array}$ & $\begin{array}{l}\text { - Data on gain are available from standard MAI } \\
\text { statistics. } \\
\text { - Data of losses are rarely available in national } \\
\text { statistics. }\end{array}$ \\
\hline
\end{tabular}

\section{Implications of country}

\section{circumstances}

The cost of measuring and monitoring degradation depends on country circumstances, which include factors such as:

- The extent of forest cover.

- The level of forest stratification (for example, Democratic Republic of Congo has only one major forest type whereas Indonesia and Mexico have four or more forest eco-types).

- The tier of carbon accounting applied.

Countries are also at different points on the forest transition curve (Figure 2), reflecting the dynamics of agriculture and forest rents over time (Angelsen, 2007). As a result, degradation is a more critical issue in some countries than others. For example, some have halted deforestation, but may be losing biomass in the remaining forests. Thus the location of a country on the forest transition curve will influence its motivation for investing in degradation accounting and the suitability of the measurement and monitoring option.

Forest transition theory suggests four categories of countries:

1. Countries and regions with low deforestation and high forest cover such as the Congo Basin and Guyana. Here, forests are relatively undisturbed, but increasing deforestation and degradation may occur in the future. These countries are likely to have the most interest in accounting for degradation because they are less likely to benefit from 'avoiding deforestation'. The stock-difference method with stratified sampling would yield the most cost-efficient method for intact forests, as proxies could be used if data prior to logging or other human intervention is not available (table 1). Countries with large areas of forest under logging concessions could costeffectively use the gain-loss method because they have the basic information needed for developing Tier 2-type reporting. Commitment to accounting for degradation might be increased by the expectation of obtaining financial support.

2. Countries with high deforestation such as (parts of) Brazil, Indonesia and Ghana. Such countries have a strong incentive to engage in deforestation accounting but are less likely to have a significant interest in accounting for degradation unless it requires little additional accounting effort. However, the exclusion of forest degradation from national REDD schemes (especially where selective logging dominates wood extraction) might lead to considerable leakage. For the same reason as for countries in Category 1, these countries would most likely prefer to use the gain-loss method.

3. Countries with low deforestation and low forest cover characterised by forest mosaics and stabilised forest areas. Deforestation rates have levelled off, either because the forest has already been largely cleared or because of strong forest protection policies. India may fall under this category and as indicated in its 2008 submission to the UNFCCC, India may be interested in reducing degradation, probably in combination with forest conservation, afforestation and reforestation, and other schemes aimed at 


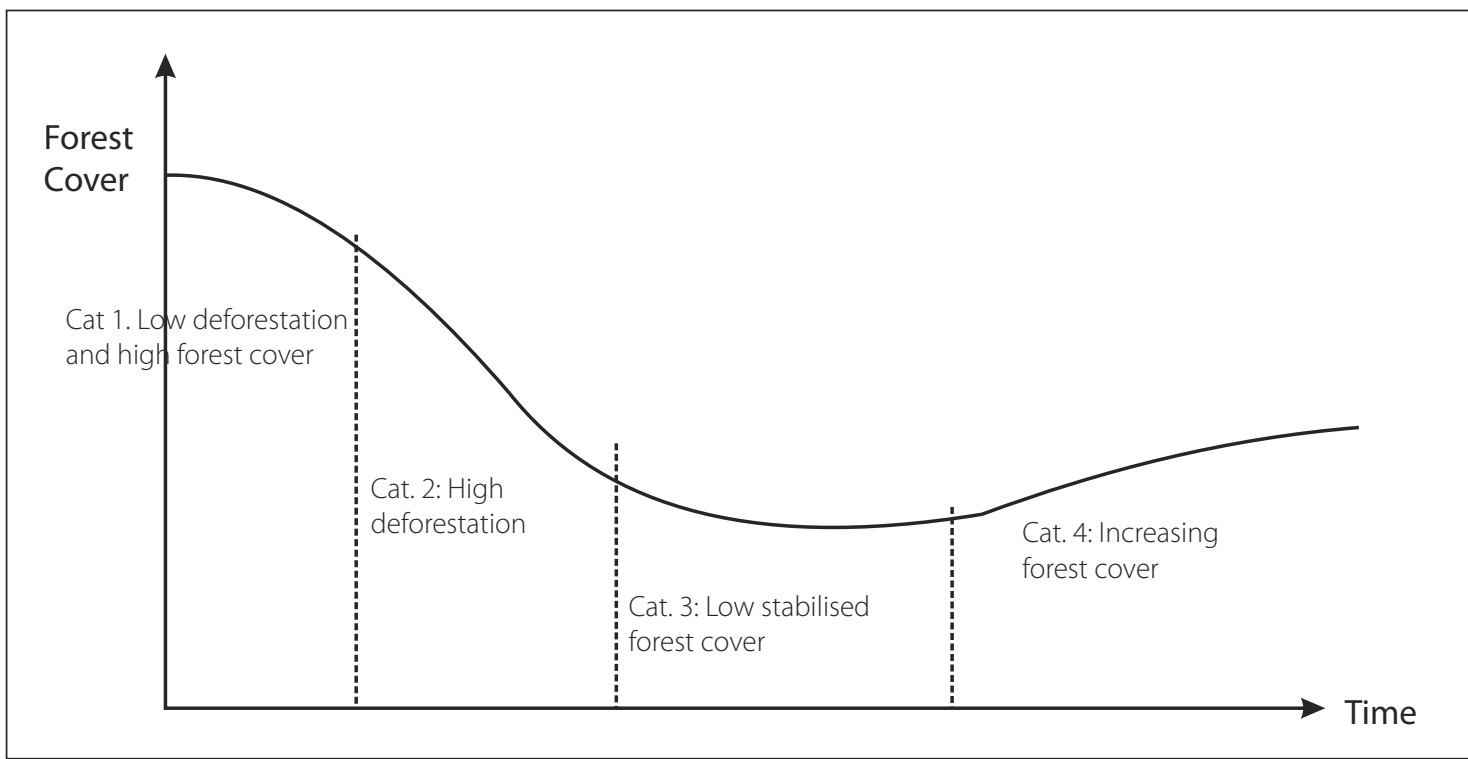

Figure 2. Categories of forest transition (adapted from: Angelsen, 2007)

enhancing forest carbon stocks. The use of the stockdifference method at Tier 2 may be appropriate; India could progress to Tier 3 as site-specific data becomes more widely available and cost-effective.

4. Countries with increasing forest cover such as China and Vietnam: These countries may have limited interest in accounting for degradation unless 'enhancing' carbon stocks is included in the scope of a REDD agreement. However, even though a country's forest area may be increasing through plantations, its existing forests may be simultaneously experiencing degradation. Success in increasing the area of forest plantations could mean these countries will prefer to present such activities as 'afforestation/ reforestation' under the Clean Development Mechanism; so much depends on whether afforestation/reforestation activities are integrated into a REDD agreement. As a result of earlier forest management activities, these countries' databases on degradation may be sufficient to provide historical reference scenarios, enabling them to adopt the stock-difference method at Tier 3.

\section{Conclusions}

The definition and MRV of degradation are more complex for degradation than for deforestation (IPCC 2003a) and require more proxy factors. The IPCC provides useful guidance through the stock-difference and gain-loss methodologies (IPCC 2006) and the use of tiers (IPCC 2003b). Where data is limited, the MRV of forest degradation could start with simple methods with default values (Tier 1) and proxies to account for emissions from different degradation activities. The uncertainties related to using simpler approaches require 'discounting' of credits, and this would provide a direct incentive to countries to upgrade their measuring and monitoring methods.

Overcoming the methodological challenges in this way enables forest degradation to be realistically included in a REDD agreement, thus making REDD more effective by accounting for a wider range of forest greenhouse gas emissions. It also increases the international equity of the REDD mechanism by encouraging participation by a wider range of countries, many of them in Africa. It is therefore important that decisions about the details of the MRV framework for degradation allow for a diversity of circumstances through permitting flexibility in designing, developing and applying methodologies.

\section{References}

Angelsen, A. 2007 Forest cover change in space and time: combining von Thünen and the forest transition. World Bank Policy Research Working Paper WPS 4117. World Bank, Washington D.C.

Asner, G.P., Knapp, D.E., Broadbent, E.N., Oliveira, O.J.C, Keller, M. and Silva, J.N. 2005 Selective logging in the Brazilian Amazon. Science 310: 480-482.

DeFries, R., Achard, F., Brown, S., Herold, M., Murdiyarso, D., Schlamadinger, B. and de Souza Jr., C. 2007 Reducing greenhouse gas emissions from deforestation in developing countries: considerations for monitoring and measuring. J. Environ. Sci. and Policy 10:385-394.

GOFC-GOLD 2008 Reducing greenhouse gas emissions from deforestation and degradation in developing countries: a sourcebook of methods and procedures for monitoring, measuring and reporting, GOFC- 
GOLD Report version COP13-2. GOFC-GOLD Project Office, Natural Resources Canada, Alberta, Canada.

Hardcastle, P.D. and Baird, D. 2008 Capability and cost assessment of the major forest nations to measure and monitor their forest carbon for Office of Climate Change. LTS International, Penicuick, UK.

IPCC 2003a Definitions and methodological options to inventory emissions from direct human-induced degradation of forests and devegetation of other vegetation types. In: Penman, J., Gytarsky, M., Krug, T., Kruger, D., Pipatti, R., Buendia, L., Miwa, K., Ngara, T., Tanabe, K. and Wagner, F. IPCC-IGES, Kanagawa (eds.).

IPCC 2003b Good practice guidance for land use, landuse change and forestry (GPG-LULUCF). In: Penman, J., Gytarsky, M., Krug, T., Kruger, D., Pipatti, R., Buendia, L., Miwa, K., Ngara, T., Tanabe, K. and Wagner F. IPCC-IGES, Kanagawa (eds.)

IPCC 2006 Guidelines for national greenhouse gas inventories - volume 4: Agriculture, land use and forestry (GL-AFOLU). http://www.ipcc-nggip.iges. or.jp

Iskandar, H., Snook L., Toma, T., MacDicken, K. and Kanninen, M. 2006 A comparison of damage due to logging under different forms of resource access in East Kalimantan, Indonesia. Forest Ecology and Management 237:83-93.

Lambin, E.F., Geist, H.J. and Lepers, E. 2003 Dynamics of land-use and land-cover change in tropical regions. Annu. Rev. Environ. Resour. 28:205-241.

Marklund, L.G. and Schoene, D. 2006 Global assessment of growing stock, biomass and carbon stock. Forest Resources Assessment Programme Working paper 106/E, Rome.

Murphy, P.G. and Lugo, A.E. 1986 Ecology of tropical dry forest. Annual Review of Ecology and Systematics 17: 67-68.

Penman, J. 2008 An exploration by the EU on methodological issues relating to reducing emissions from forest degradation in developing countries. UNFCCC Informal Meeting of Experts. Bonn, 20-21 October 2008. http://unfccc.int/methods_science/ redd/items/4579.php

Schelhas, J. and Sanchez-Azofeifa, G.A. 2006 Post-frontier forest change adjacent to Braulio Carrillo National Park, Costa Rica. Human Ecology 34:407-431.

Skutsch, M. and Trines, E. 2008 Operationalising reduced degradation within REDD. http://www. communitycarbonforestry.org

For further information, please contact:

Daniel Murdiyarso d.murdiyarso@cgiar.org

Margaret Skutsch m.skutsch@utwente.nl

Manuel Guariguata m.guariguata@cgiar.org

Markku Kanninen m.kanninen@cgiar.org

Cecilia Luttrell c.luttrell@cgiar.org

Pita Verweij P.A.Verweij@uu.nl

Osvaldo Stella Osvaldostella@ipam.org.br

For general inquiries contact cifor@cgiar.org
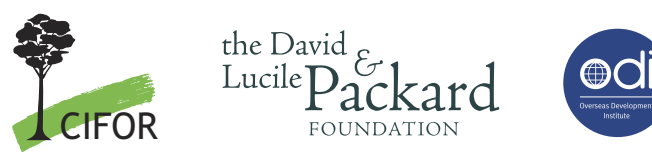

Project funding was received from the David and Lucile Packard Foundation

Center for International Forestry Research (CIFOR) advances human well-being, environmental conservation, and equity by conducting research to inform policies and practices that affect forests in developing countries. CIFOR is one of 15 centres within the Consultative Group on International Agricultural Research (CGIAR). CIFOR's headquarters are in Bogor, Indonesia. It also has offices in Asia, Africa and South America. CIFOR works in over 30 countries worldwide and has links with researchers in 50 international, regional and national organisations. www.cifor.cgiar.org 